\title{
CHANGE OF BEARING CAPACITY CHARACTERISTICS OF ASPHALT PAVEMENT
}

Time succession of data for monitored variable parameter of pavement state is the first step in development of degradation models and determination of degradation functions. Procedure used for characteristics of bearing capacity is described in the paper.

Data from long time monitored (since 1995) test section on road network were used. First of all homogeneity of subgrade was tested. The deflections at distance of $1500 \mathrm{~mm}$ from load centre were used for this purpose. Data that met criteria of homogeneity were corrected taking into account influence of temperature. Two characteristics of bearing capacity (central deflection and surface curvature index) were evaluated in relation to number of heavy vehicles that had passed test section.

Results showed that investigated characteristics of pavement bearing capacity changed in time. It was stated that tendency of development was not very clear because values oscillated in the narrow range. Generally saying the bearing capacity of tested pavement has not changed since 1995 significantly.

\section{Introduction}

Prognosis of change for variable parameters of pavements is a very important element of Pavement Management Systems (PMS). Degradation models and functions have to be determined for this purpose. Development of degradation models and determination of degradation functions requires in the first step time succession of data for monitored variable parameter of pavement. Deflections of pavement are the most used characteristics in the case of bearing capacity of pavement but other characteristics calculated from deflections (modulus, indices etc.) can be used too. Changes of deflections or other parameters at determined test points are usually related to traffic intensity that is obviously expressed in number of heavy vehicles or in equivalent standard axle loads (ESAL).

Long time repeated measurements on real pavements or accelerated testing on testing tracks have to be done for development of degradation model. The first possibility was chosen in Slovakia. 23 test sections (each of them with length of $1 \mathrm{~km}$ ) on road network were chosen and measurements have been repeated since 1995 twice a year. The pavement structure of twelve sections is flexible and eleven sections have semi-rigid pavement structure. Aim of the paper is presentation of time succession of data for one of the test sections with flexible pavement. Deflections at centre of load and surface curvature indexes were evaluated and related to number of heavy vehicles that passed through the section.

\section{Checking and selection of data}

Deflections were regularly measured in spring and autumn but temperature conditions and moisture of subgrade were different during the measurements. Moreover, load force varied in the range of $\pm 5 \mathrm{kN}$ about $50 \mathrm{kN}$. Therefore, corrections of measured deflection were necessary.

All central deflections were recalculated to equivalent load force of $50 \mathrm{kN}$ (one half of equivalent standard axle load of $100 \mathrm{kN}$ ) according to [1] in the first step.

Second stage was related to evaluation of subgrade and its homogeneity. Deflections at distance of $1500 \mathrm{~mm}$ from load centre were used. An aim was to discard measurements that were carried out during conditions in subgrade that markedly differed from most of the measurements (frozen or very wet subgrade). Values at all tested points were checked and examples for values at some points are in Fig. 1.

It is evident from Fig. 1 that values of deflections at distance of $1500 \mathrm{~mm}$ from load centre are variable in time, time behaviour is different at individual points and there are values that are very different in comparison to other values for the same test point. Coefficient of variation was used for homogeneity test and value of 0.1 was used as criterion. When the criterion was not met outliers were identified. The value that was out of range of

\footnotetext{
* Jozef Komacka

Faculty of Civil Engineering, University of Zilina, Slovakia, E-mail: komacka@fstav.utc.sk
} 


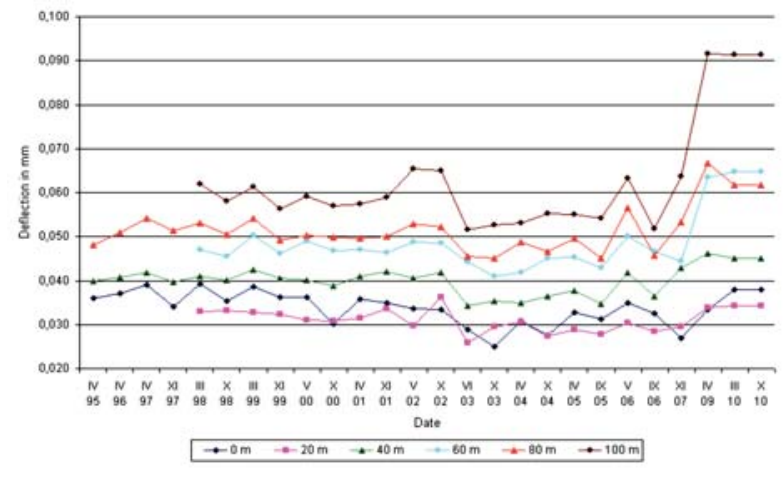

Fig. 1 Time succession of deflections at distance of $1500 \mathrm{~mm}$ from load centre for beginning of the test section

$$
\bar{w} \pm \sigma
$$

where:

$\bar{w}$ is an average deflection

$\sigma$ - standard deviation

was considered as an outlier. These values were discarded and average deflection at distance of $1500 \mathrm{~mm}$ from load centre was calculated for each test point. Visual display (Fig. 2) indicated homogeneity of subgrade for the whole test section. As can be seen subgrade on test section is not homogenous because spread of average deflections is very large. It was confirmed by statistical evaluation using coefficient of variation (value 0.235 ). Moreover, modulus of subgrade calculated according to equation published in [2] varied from $90 \mathrm{MPa}$ to $400 \mathrm{MPa}$. Therefore, values of deflections were distributed into groups. The range of values in each of the groups was not higher than $40 \mathrm{MPa}$. Median of data was used as initial value for determination of these groups. Only two groups (range of deflections $0.05 \mathrm{~mm}-0.059 \mathrm{~mm}$ and $0.060 \mathrm{~mm}-0.069 \mathrm{~mm}$ respectively) were chosen for next evaluation taking into account number of values in individual groups (Fig. 3). Positions of test points (chainage) for chosen groups are in Tab. 1.

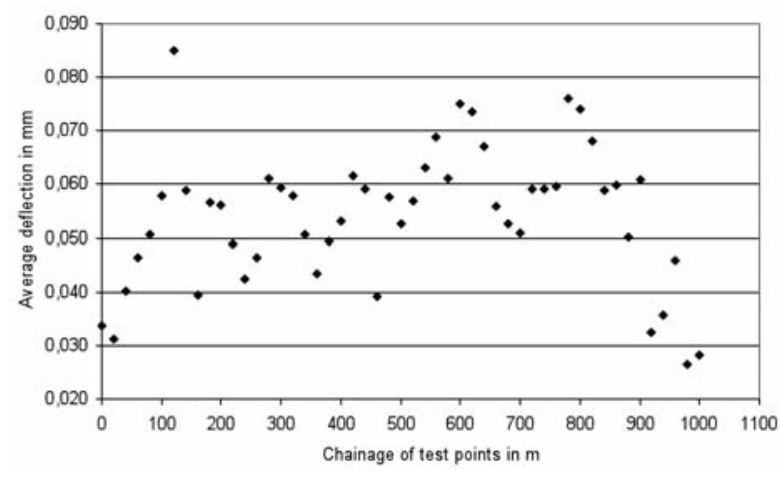

Fig. 2 Average values of deflections at distance of $1500 \mathrm{~mm}$ from load centre

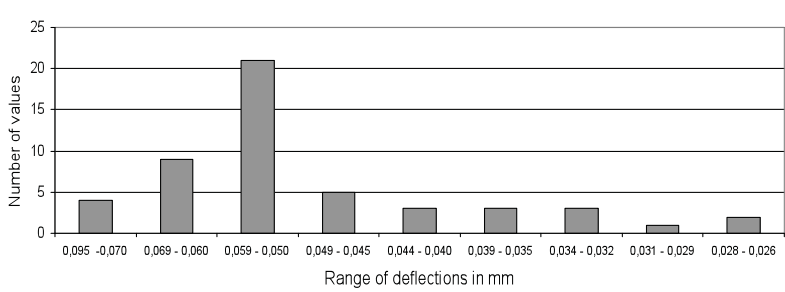

Fig. 3 Number of values in individual groups of deflections

Test points chosen from homogeneity

Tab. 1 of subgrade point of view

\begin{tabular}{|l|l|}
\hline Range of deflections & Chainage of test points \\
\hline \multirow{2}{*}{$0.05 \mathrm{~mm}-0.059 \mathrm{~mm}$} & $\begin{array}{l}80,100,140,180,200,220,300,320,340, \\
380,400,440,480,500,520,660,680,700, \\
720,740,840,860,880\end{array}$ \\
\hline $0.060 \mathrm{~mm}-0.069 \mathrm{~mm}$ & $280,420,540,560,580,640,760,820,900$ \\
\hline
\end{tabular}

\section{Corrections of data}

Moisture of subgrade and temperature of asphalt layers are two main factors that have to be taken into account when long time measured data are used for determination of a degradation model.

Of course, moisture of subgrade varies during long period. Higher moisture of subgrade leads to lower stiffness of subgrade, thereby to lower bearing capacity of pavement expressed by higher value of deflections. It is known that deflection recorded by the farthest sensor of FWD could be used for evaluation of bearing capacity of subgrade. In this case it is a sensor at distance of $1500 \mathrm{~mm}$. Variability of deflections at this distance is evident from Fig. 1 and necessity to recalculate deflections to average moisture content (or average stiffness) of subgrade is clear. Correction of deflections was carried out according to the conclusions in [3]. There was stated that stiffness of subgrade changes the numeric value of deflections but does not change the shape of a deflection bowl. It only shifts a bowl in a parallel way in vertical direction. Corrections were calculated from equation

$$
w_{i, 50, v}=w_{i, 50}+\left(w_{1500,50, \text { avg }}-w_{1500,50}\right)
$$

where:

$w_{i, 50, v} \quad$ - deflection at distance of " $\mathrm{i}$ “ from load centre recalculated to load of $50 \mathrm{kN}$ and average moisture content $[\mathrm{mm}]$

- deflection at distance of "i“" from load centre recalculated to load of $50 \mathrm{kN}$ [mm];

$w_{1500,50, \text { avg }}$ - average deflection at distance of $1500 \mathrm{~mm}$ from load

$\begin{aligned} w_{1500,50, \text { avg }} & \text { average deflection at distance of } 1500 \mathrm{~mm} \text { from load } \\ & \text { centre recalculated to load of } 50 \mathrm{kN}[\mathrm{mm}] ;\end{aligned}$ - deflection at distance of $1500 \mathrm{~mm}$ from load centre recalculated to load of $50 \mathrm{kN}[\mathrm{mm}]$.

Temperature of asphalt layers influences their stiffness (higher temperature leads to lower stiffness) and consequently values of 
deflections (higher temperature leads to higher deflections). As repeated measurements of deflections were carried out at different temperatures it is very important to make temperature corrections, that means, to recalculate deflection to equivalent temperature of asphalt layers. The value of $+20{ }^{\circ} \mathrm{C}$ is used in Slovakia. The procedure determined in [1] was used. The average temperature of asphalt layers was determined using temperature gradients in asphalt layers of pavements presented in [4] according to equation

$$
T_{o s f}=T_{p}+\Delta T,
$$

where:

$T_{p}$-temperature of pavement surface during measurement of deflection $\left[{ }^{\circ} \mathrm{C}\right]$;

$\Delta T$ - temperature difference between temperature of pavement surface and average temperature of asphalt layers according to $[1]\left[{ }^{\circ} \mathrm{C}\right]$

Consequently, recalculation of deflections to equivalent temperature of $+20{ }^{\circ} \mathrm{C}$ was carried out using the formula

$$
w_{T 20}=w_{T}+k_{T(R)} \cdot\left(20-T_{a s f}\right),
$$

where:

$w_{T 20}$-deflection recalculated to equivalent temperature of $20^{\circ} \mathrm{C}$ [mm];

$w_{T}$-deflection measured at temperature $\mathrm{T}[\mathrm{mm}] ;$

$T_{\text {asf }}$ - average temperature of asphalt layers $\left[{ }^{\circ} \mathrm{C}\right]$;

$k_{T(R)}$-correction coefficient for sensor at distance $\mathrm{R}$.

Values of correction coefficients were determined for each sensor at all evaluated test points using relationships between average temperature of asphalt layers and deflection (see Fig. 4).

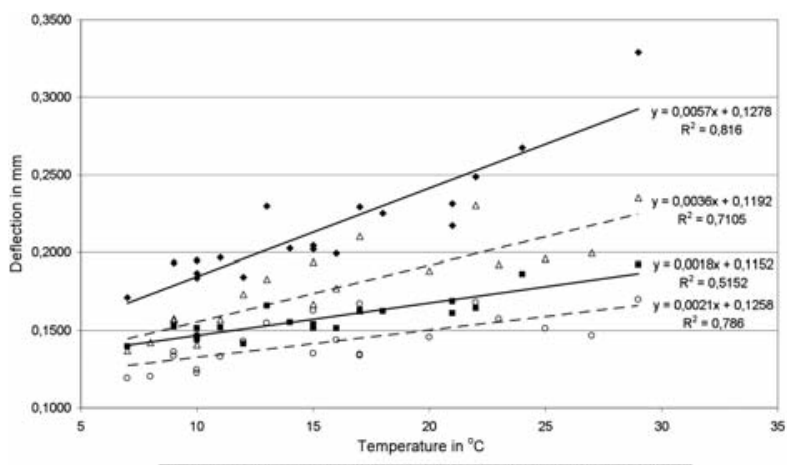

Fig. 4 Correlation between average temperature of asphalt layers and deflection

\section{Change of deflections}

As time succession of recalculated deflections did not express the influence of traffic intensity it was necessary to determine the number of heavy vehicles that had passed through the test section between individual measurements. Outputs of statewide traffic censuses from 1995, 2000 and 2005 were used. When central deflections were plotted against number of heavy vehicles it was stated that the change of central deflections was similar (Fig. 5) and it was possible to use average of all chosen test points for evaluation of change in central deflection.

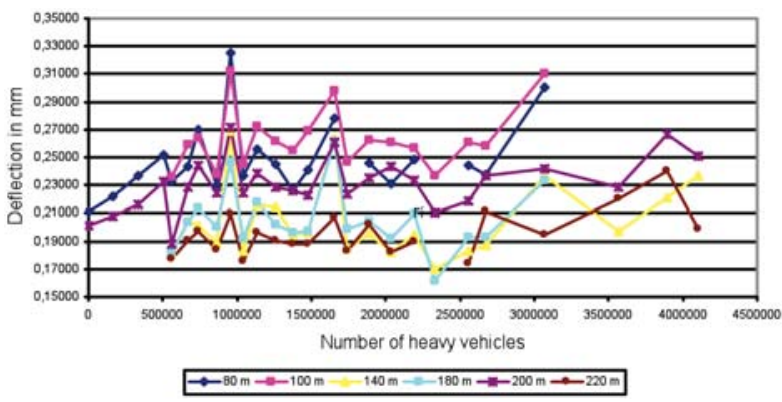

Fig. 5 Deflection versus traffic intensity

Final outputs showed in Fig. 6 document that there is not clear development of central deflection in this case. Moreover, relationship between change of central deflection and number of heavy vehicles is not very strong (value of correlation coefficient is relatively low). One of reasons of these findings could be the fact that central deflection reflects reaction of whole pavement. Therefore, surface curvature index (SCI) was chosen for investigation in the next stage because it reflects only stiffness of asphalt layers of pavement.

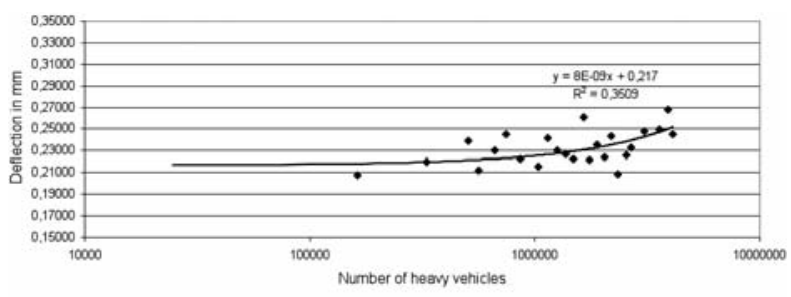

Fig. 6 Change of central deflection against traffic intensity

The values of recalculated deflections were used for calculation of SCI according to following equation

$$
S C I_{300}=w_{0,50, T 20}-w_{300,50, T 20}
$$

where:

$w_{0,50, T 20}$ - deflection at load centre recalculated to load of $50 \mathrm{kN}$ and equivalent temperature of $20{ }^{\circ} \mathrm{C}$ [mm];

$w_{300,50, T 20}$ - deflection at distance of $300 \mathrm{~mm}$ from load centre recalculated to load of $50 \mathrm{kN}$ and equivalent temperature of $20{ }^{\circ} \mathrm{C}$ [mm].

The values of $\mathrm{SCI}_{300}$ were plotted against the number of heavy vehicles that had passed through test section (Fig. 7). As in the 
case of central deflection it was possible to state that the change of $S_{300}$ at all chosen test points was similar and average values could be used.

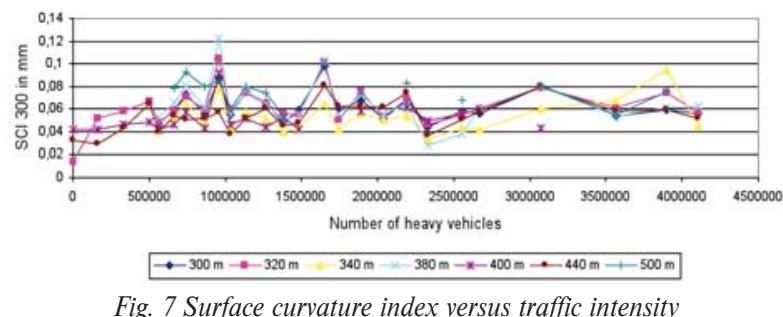

Results given in Fig. 8 are similar to the outputs for central deflection. It means the conclusions are the same as in the previous case - not clear development of SCI and not very strong relationship between SCI development and increase of traffic intensity.

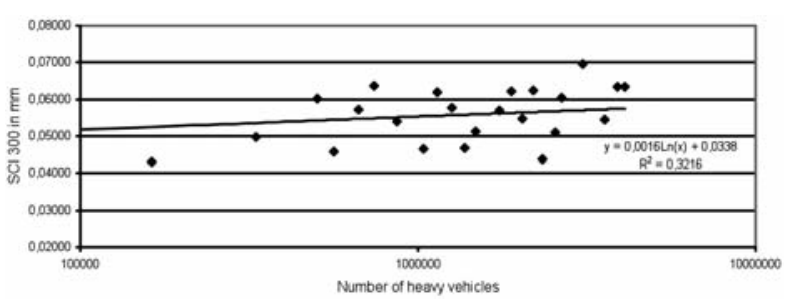

Fig. 8 Change of surface curvature index in relation to traffic intensity

\section{Conclusions}

Results of long term measurements at the test section show that characteristics of pavement bearing capacity change in time. Moisture content of subgrade and temperature of asphalt layers influence these changes.

After corrections of deflections with respect to the mentioned factors it was stated that tendency of development was not very clear because values oscillated in the narrow range. It is valid for central deflection and surface curvature index too. Generally saying the bearing capacity of tested pavement has not changed since 1995 significantly. As for relationship between characteristics of bearing capacity and number of heavy vehicles it was found that this dependence is not very strong. These findings are not quite in conformity with theoretical assumptions that suppose increase of deflections with traffic intensity. May be the number of heavy vehicles that had passed through the test section was too small to influence markedly characteristics of bearing capacity.

Anyway, performed measurements enlarge database of data that can be used for determination of degradation model of bearing capacity of asphalt pavements. It would be necessary to carry out the diagnostics of pavement bearing capacity for all test sections during next years according to the same methodology. New data could be used for a modification of the theoretical degradation model that is used for prediction of performance of asphalt pavements.

\section{References}

[1] TP 01/2009 Measuring and Evaluation of Bearing Capacity of Asphalt Pavements Using FWD KUAB (in Slovak), MDPaT SR, Bratislava, 2009.

[2] KOMACKA, J.: Diagnostics of Subgrade of Asphalt Pavements Using FWD Device and Obtained Results (in Slovak), Silnicni obzor, No. 9, 2000, p. 197-201.

[3] KOMACKA, J.: Diagnostics and Evaluation of Bearing Capacity of Pavement from Road Database Point of View (in Slovak), PhD thesis, Zilina : VSDS Zilina, 1996, p. 142.

[4] KOMACKA, J., KORENKO, M., PIALA, J.: Relation of Temperature Changes in Asphalt Pavements to Pavement Bearing Capacity Evaluation, Communications - Scientific Letters of the University of Zilina, Vol. 9, No. 3, 2007, pp. 33-36, ISSN 1335-4205. 